\title{
CoO@MnFe2O4 Octahedron-Shaped Nanocages
}

Benito Rodríguez-González ${ }^{1}$, Alicia Prieto-Troitiño², Rosalía Mariño-Fernández ${ }^{2}$, Miguel A. RamosDocampo $^{2}$ and Verónica Salgueiriño ${ }^{2}$

${ }^{1 .}$ Centro de Apoio Científico e Tecnolóxico á Investigación (CACTI), Universidade de Vigo, 36310 Vigo, Spain.

2. Departamento de Física Aplicada, Universidade de Vigo, 36310 Vigo, Spain.

Magnetic nanoparticles have promising applications in magnetic separation, sensing and biodetection [1]. Hollow and pierced magnetic nanoparticles, called magnetic nanocages, have large surface area, low density and peculiar magnetic properties. This makes $\mathrm{Fe}_{3} \mathrm{O}_{4}$ nanocages promising candidates for further applications in catalysis, hyperthermia or drug-delivery.

In this work we focus on the transmission electron microscopy (TEM) characterization of $\mathrm{CoO} @ \mathrm{MnFe}_{2} \mathrm{O}_{4}$ octahedron-shaped nanocages obtained after a multi-step process. A $200 \mathrm{kV}$ transmission electron microscope (JEOL JEM 2010F TEM) was used to carry out different electron microscopy characterization techniques like high resolution transmission electron microscopy (HRTEM), scanning transmission electron microscopy (STEM), electron energy loss spectroscopy (EELS) and energy dispersive spectroscopy (EDS). Besides, with the obtained images we performed Fourier analysis to demonstrate the epitaxial growth and the setup of the $\mathrm{MnFe}_{2} \mathrm{O}_{4}$ layer.

$\mathrm{CoO} @ \mathrm{MnFe}_{2} \mathrm{O}_{4}$ nanocages were obtained using pre-obtained octahedron-shaped $\mathrm{CoO}$ nanoparticles as templates to first deposit a magnetite $\left(\mathrm{Fe}_{3} \mathrm{O}_{4}\right)$ layer [2-3]. After that, a solid-state reaction transforms the $\mathrm{Fe}_{3} \mathrm{O}_{4}$ into $\mathrm{MnFe}_{2} \mathrm{O}_{4}$, and the former solid nanoparticles into $\mathrm{CoO} @ \mathrm{MnFe}_{2} \mathrm{O}_{4}$ nanocages. Interesting, TEM results show the octahedron shape is maintained along the process, despite the formation of large holes piercing the facets and the volume of the nanoparticle (Figure 1). The deposited shell is $3 \mathrm{~nm}$ thick and the Fourier transform analysis showed an almost perfect epitaxial growth of the $\mathrm{MnFe}_{2} \mathrm{O}_{4}$ over the remains of the $\mathrm{CoO}$ core, as it was demonstrated before in the case of the solid $\mathrm{CoO} @ \mathrm{Fe}_{3} \mathrm{O}_{4}$ octahedronshaped nanoparticles [3]. EDS confirmed the composition of the particles, and EELS showed the presence of $\mathrm{Mn}$ and Fe predominantly in the shell while some $\mathrm{CoO}$ still is located in the core.

\section{References:}

[1] P. Tartaj et al., J. Phys. D: Appl. Phys. 36 (2003) R182.

[2] N. Fontaíña-Troitiño et al., Nano letters. 14 (2014) p. 640.

[3] N. Fontaíña-Troitiño et al., Chem. Mater. 26 (2014) p. 5566. 

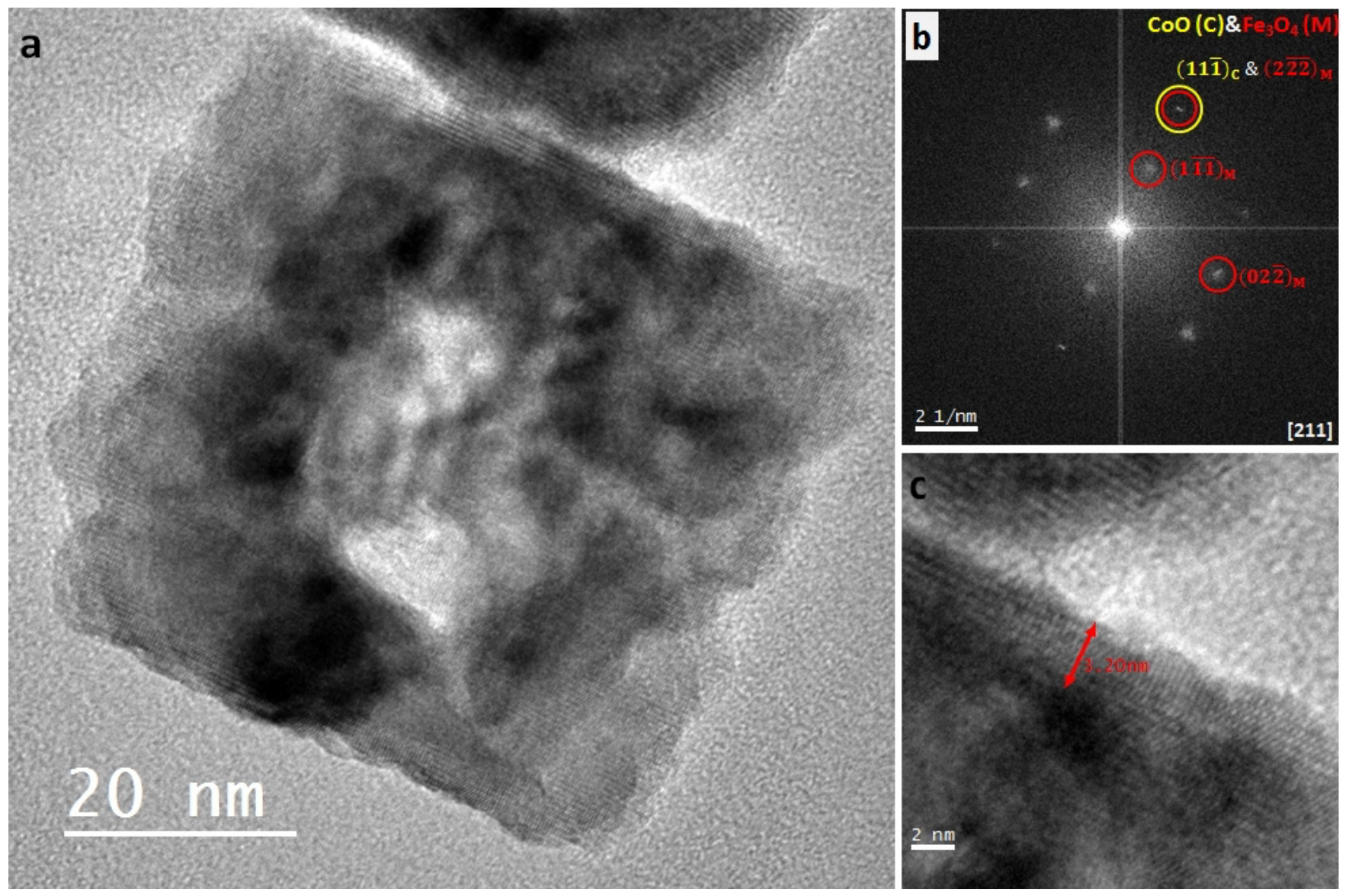

Figure 1. (a) TEM image of a $\mathrm{CoO} @ \mathrm{MnFe}_{2} \mathrm{O}_{4}$ nanocage in the [211] zone axis. (b) Fourier transform of the nanocage showed in (a) displaying spots corresponding to $\mathrm{CoO}$ and $\mathrm{Fe}_{3} \mathrm{O}_{4}$ aligned. (c) Image showing the thickness of the $\mathrm{MnFe}_{2} \mathrm{O}_{4}$. 